\title{
Septum Pellucidum Cavernoma: A Case Report and Anatomical Consideration of an Extremely Rare Lesion
}

\author{
Aline Lariessy CAMPOS PAIVA ${ }^{1}$, Renan Maximillian LOVATO'ㄹ, João Luiz VITORINO ARAUJO', \\ José Carlos ESTEVES VEIGA ${ }^{2}$ \\ 'Santa Casa de São Paulo School of Medical Sciences, Discipline of Neurosurgery, São Paulo (SP), Brazil \\ ${ }^{2}$ Santa Casa de São Paulo School of Medical Sciences, Discipline of Neurosurgery, Department of Surgery, São Paulo (SP), Brazil
}

Corresponding author: Aline Lariessy CAMPOS PAIVA lariessy@hotmail.com

\section{ABSTRACT}

Cavernous angiomas (cavernomas) are vascular malformations of the brain characterized by abnormal capillaries. Ventricular cavernomas are considered rare; however, an extremely unusual topography is the septum pellucidum, with only five reported cases in the English literature. These malformations may rupture and cause very large hematomas, leading to neurological impairment. Cavernomas can be familial or sporadic; additionally, these may appear following brain radiotherapy in extremely rare cases.

Herein, we present an extremely rare and unique case of a septum pellucidum cavernoma that occurred in a young male who had previously undergone brain radiotherapy in childhood due to acute lymphoid leukemia. Following presentation, he was diagnosed with generalized seizures. The cavernoma was resected via an anterior interhemispheric transcallosal approach, following which the patient remained stable without neurological sequelae.

To conclude, ventricular cavernomas are rare lesions, especially when located at the septum pellucidum, thus constitute a challenging neurosurgical approach.

KEYWORDS: Cavernous hemangioma, Septum pellucidum, Radiotherapy, Cerebral ventricle neoplasm, Cerebral hemorrhage

\section{INTRODUCTION}

$(1$ avernous angiomas (cavernomas) are rare lesions of the central nervous system (CNS) categorized as vascular malformations $(5 \%-13 \%)$ (1). They may present as brain hemorrhage and seizures in young adults; in these patients, cavernomas generally occupy the brain parenchyma or ventricular system (2). Cavernomas may occur in familial or sporadic forms (6). Further, de novo growth has been reported, especially in pediatric patients with a history of CNS radiotherapy (6).

Involvement of the ventricular system is very rare $(2.5 \%-$ $10.8 \%$ ) (6). However, a unique and rare topography is the septum pellucidum, which is surgically considered challenging. To date, only five cases have been reported in the English literature $(1,4,5,7,8)$ (Table I). In this report, we describe the sixth case of this rare entity in a patient without a familial history of cavernoma who had undergone whole-brain radiotherapy in his childhood.

\section{CASE REPORT}

A 19-year-old male presented to a neurosurgical outpatient clinic after experiencing brain trauma injury and seizures. Neurological examination revealed normal findings; however, brain computed tomography revealed a lesion with a ventricular topography. The patient's medical history included diagnosis of acute lymphoid leukemia (ALL) that was treated 14 years prior using chemotherapy and radiotherapy.

At that time, the patient was 5 years old and had undergone prophylactic whole-brain irradiation. Notably, CNS investigation did not reveal any involvement - cerebro spinal fluid, and
Aline Lariessy CAMPOS PAIVA (I) : 0000-0002-1228-531X Renan Maximillian LOVATO (10) : 0000-0002-9239-008X
João Luiz VITORINO ARAUJO (D) : 0000-0002-6539-6718 José Carlos ESTEVES VEIGA (D): 0000-0002-7723-4396 
Table I: Reported Cases of Septum Pellucidum Cavernoma in English Language

\begin{tabular}{|c|c|c|c|c|c|c|c|}
\hline Author/Year & Age & Sex & $\begin{array}{l}\text { Clinical } \\
\text { Feature }\end{array}$ & $\begin{array}{l}\text { Family } \\
\text { History }\end{array}$ & $\begin{array}{c}\text { CNS } \\
\text { Radiotherapy }\end{array}$ & Radiology & $\begin{array}{l}\text { Surgical } \\
\text { Approach }\end{array}$ \\
\hline $\begin{array}{l}\text { Kasliwal and } \\
\text { Sharma, } 2011 \text { (4) }\end{array}$ & 55 & $\mathrm{M}$ & Headache & No & No & $\begin{array}{c}\text { MRI brain showed heterogenous } \\
\text { lesion on T1WI } \\
\text { and T2WI, blooming on } \\
\text { Gradient echo }\end{array}$ & $\begin{array}{l}\text { Right frontal } \\
\text { transcortical }\end{array}$ \\
\hline $\begin{array}{l}\text { Muzumdar D et al., } \\
2015(7)\end{array}$ & 35 & $\mathrm{~F}$ & Headache & No & No & $\begin{array}{l}\text { MRI showing T2 mixed intensity } \\
\text { T2-weighted } \\
\text { arising from the inferior aspect } \\
\text { of the septum pellucidum }\end{array}$ & $\begin{array}{l}\text { Anterior } \\
\text { interhemispheric } \\
\text { transcallosal }\end{array}$ \\
\hline $\begin{array}{l}\text { Picolas C et al., } \\
2016(8)\end{array}$ & 58 & M & $\begin{array}{l}\text { Headache, } \\
\text { personality } \\
\text { and memory } \\
\text { changes }\end{array}$ & No & No & $\begin{array}{c}\text { MRI showed an oval tumor } \\
\text { with mixed dispersed iso- and } \\
\text { hyperintense } \\
\text { nodular loci in T1 sequence and } \\
\text { hypointense with dispersed } \\
\text { nodular hyperintense loci in T2. }\end{array}$ & $\begin{array}{l}\text { Inferior parietal } \\
\text { transcortical } \\
\text { transventricular }\end{array}$ \\
\hline $\begin{array}{l}\text { Paiva A et al. } \\
\text { (present case) }\end{array}$ & 19 & $M$ & $\begin{array}{l}\text { Epileptic } \\
\text { seizure }\end{array}$ & No & Yes & $\begin{array}{l}\text { T1-weighted MRI showed } \\
\text { a mixed signal mass at } \\
\text { septum pellucidum without } \\
\text { hydrocephalus }\end{array}$ & $\begin{array}{l}\text { Anterior } \\
\text { interhemispheric } \\
\text { transcallosal }\end{array}$ \\
\hline
\end{tabular}

CNS: Central nervous system, F: Female, M: Male, MRI: Magnetic resonance imaging.

magnetic resonance imaging (MRI) findings were normal. In 2002 , the total radiation dose was $18 \mathrm{~Gy}$ administered over 12 days. Based on the chemotherapy strategy, he received cycles of methotrexate treatment in 2002 , which was repeated in 2004.

For a comprehensive investigation of this lesion, the patient underwent $\mathrm{MRI}$, which revealed the presence of a nodular lesion with a heterogeneous sign on T1-weighted, T2weighted, and FLAIR modalities; the lesion exhibited septum pellucidum topography (Figure 1A, B). The initial hypothesis was a cavernoma based on these MRI characteristics.

An anterior interhemispheric transcallosal approach was used for corrective surgery (Figure 2). Histopathological analysis confirmed the suspicion of a cavernoma. The patient continued to exhibit no neurologic deficits. MRI performed during the first postoperative 24 hours confirmed complete removal of the lesion (Figure 3). After 60 hours of observation, the patient was discharged.

Gradually, anticonvulsant administration was withdrawn, and the patient remarkably showed no signs of epilepsy. A subse- quent neuropsychological evaluation revealed no changes in memory relative to that determined in the preoperative evaluation.

\section{DISCUSSION}

Cavernomas are CNS vascular malformations comprising clusters of abnormal capillaries surrounded by hemosiderin deposits and a gliotic margin (6). These lesions exhibit a high risk of bleeding and serve as a differential diagnosis for parenchymal hemorrhage, particularly in younger patients. Ventricular bleeding may be another catastrophic manifestation $(4,6)$.

Occasionally, large lesions may be asymptomatic. Seizures, headache, and focal neurologic deficits comprise a subset of manifestations. Lesions in supratentorial compartments exhibit a prevalence of $70 \%-80 \%$ (6). However, bleeding is more common in infratentorial cavernomas, with a prevalence of $3.8 \%$ relative to the prevalence of supratentorial cavernomas $(0.4 \%)(6)$. These malformations can be sporadic or occur in relation to an inherited pattern. Approximately $40 \%-60 \%$ of 


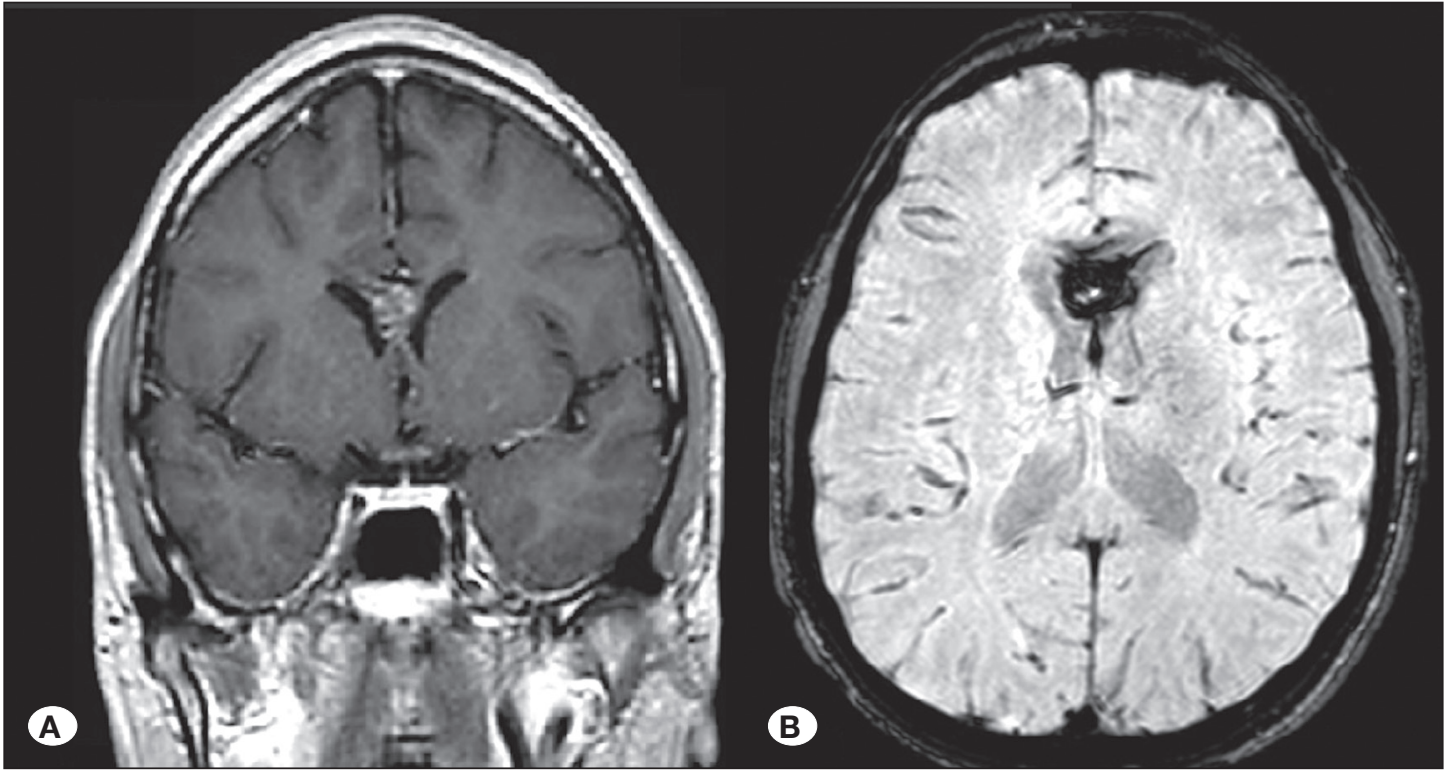

Figure 1: A) T1W

contrast enhanced coronal MRI showing a heterogeneous lesion at septum pellucidum topography;

B) axial SWI MRI showing signs of previous bleeding heterogeneous lesion with hemosiderin inside.

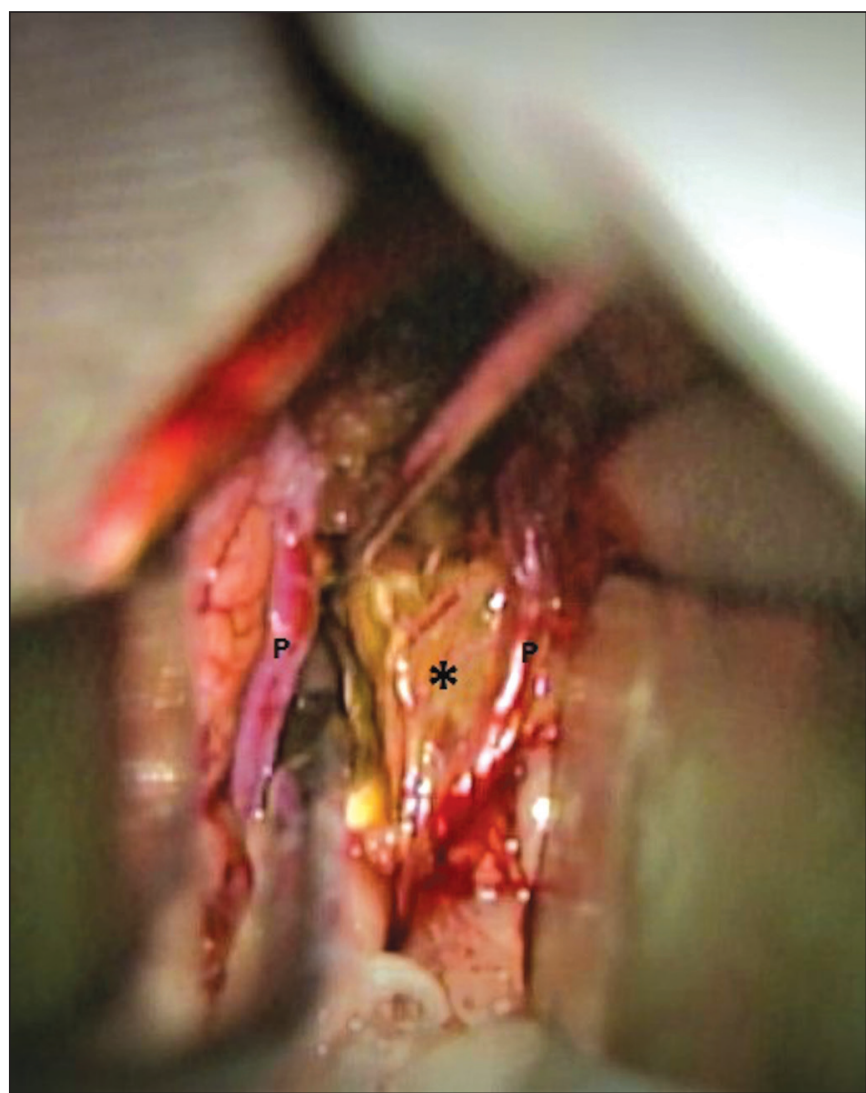

Figure 2: Microscopic intraoperative feature reveling a yellowish lesion; *: cavernoma; P: posterior choroidal arteries.

cavernomas occur in a familial form; notably, these types often involve multiple cavernomas (6).

Regarding sporadic cavernomas, there may be a relationship between the application of radiotherapy and onset of cavernoma, primarily in children who undergo cranial radiation in

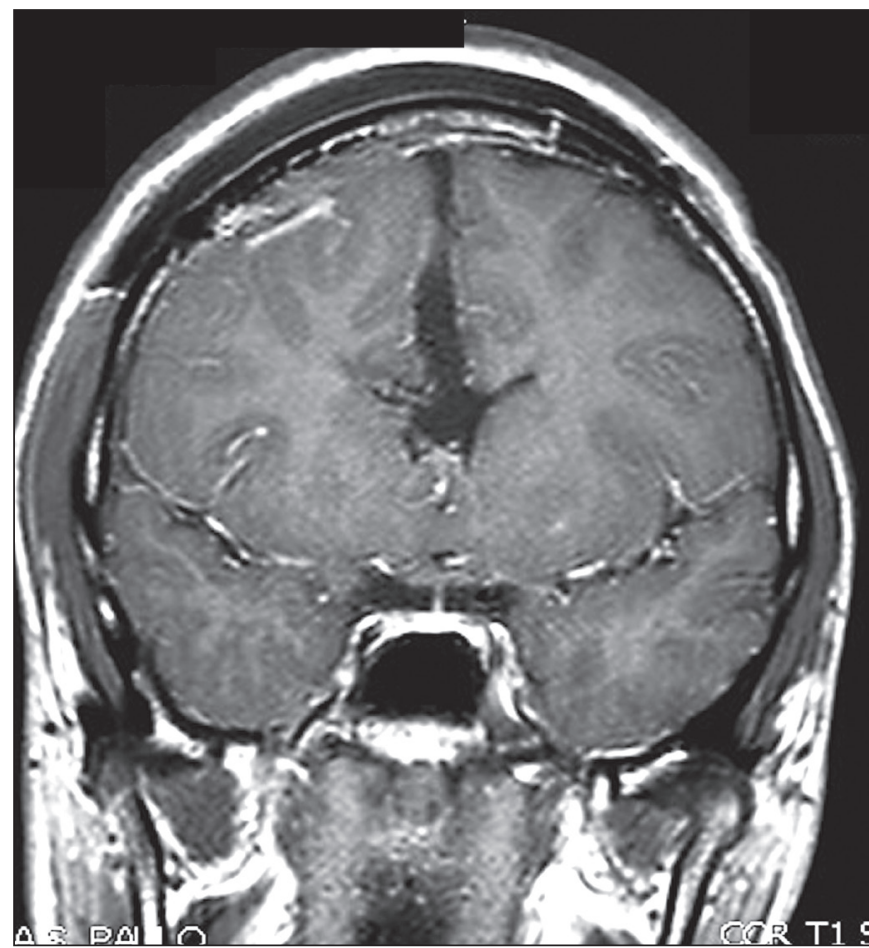

Figure 3: Immediate post-operative T1- weighted contrast enhanced coronal MRI showing complete resection.

childhood; in fact, most instances of radiotherapy-associated cavernomas are related to the treatment of hematologic malignancies (2). There are some prior reports in the literature, and a relationship between radiotherapy dose and the risk of developing a radiation-induced cavernous hemangioma $(\mathrm{RICH})$ has been proposed $(3,6)$. The primary hypothesis regarding the mechanism underlying $\mathrm{RICH}$ physiopathology is that $\mathrm{RICH}$ develops from a de novo response to radiation, thereby inducing histological changes in brain parenchyma. 
Currently, there is a lack of available information regarding the behavior of such lesions because of the small number of case reports on this peculiar entity.

The patient described in this report had previously undergone prophylactic whole-brain radiotherapy in his childhood as a treatment for ALL, during which neurological involvement was not observed. Therefore, the septum pellucidum cavernoma might be a result of radiation exposure and be appropriately classified as $\mathrm{RICH}$.

$\mathrm{MRI}$ is the gold standard neuro imaging modality for cavernoma diagnosis, in so far as these lesions are angiographically occult malformations. Nevertheless, developmental venous anomalyis typically associated with and is visible during angiography and MRI (6). In the parenchymal form, a hypointense ring is observed on T1- and T2-weighted modalities due to hemosiderin deposits from recurring microhemorrhages (6).

Because typical images have not been established, ventricular cavernomas exhibit several differential diagnoses, including arteriovenous malformations, astrocytomas, choroid plexus papillomas, ependymomas, and colloid cysts (1). Insome reports, biopsy was initially performed because MRI results supported a hypothesis of brain tumor (5). They are less frequent $(2.5 \%-10.8 \%)(5)$, and the first description was done in 1905 by Finkelburg $(2,6)$. Regarding ventricular topography, lateral ventricles are most commonly affected (5). In this patient, the initial MRI was highly suggestive of a cavernous angioma. An anterior transcallosal interhemispheric approach was found to be an appropriate surgical approach for the lesions in this topography because it provides good visualization of the anterior ventricular structures (Figure 2).

Furthermore, septum pellucidum cavernomas are extremely rare ventricular lesions; as noted above, only five cases have been reported in the English literature $(1,4,5,7,8)$ (Table I). Cavernomas of the septum pellucidum do not exhibit any specific clinical presentation; however, patients might demonstrate memory disturbances and the signs and symptoms of hydrocephalus owing to the obstruction of the foramen of Monro (6).

While using neurosurgical approaches, damage to neighboring structures should be minimized, particularly the structures related to memory, such as the fornices, emphasizing the criticality of surgical route selection. The anterior transcallosal approach is adequate and is often superior to the ventricular transcortical approach for midline lesions without hydrocephalus as well as in cases where in the frontal lobe thickness is greater than $30 \mathrm{~mm}$, as observed in the present case (9). Therefore, the anterior transcallosal approach (Figure 2) was used, following which the patient did not exhibited neurologic deficits.

\section{CONCLUSION}

In young patients, cavernomas constitute an important type of vascular malformation associated with brain hemorrhage. Although rare, their ventricular forms should be considered in differential diagnosis during MRI evaluation. The septum pellucidum is an extremely rare topography; considering its proximity with noble structures, the corrective surgical approach must be judiciously planned. In patients who have previously undergone brain irradiation, the diagnosis of cavernoma must be strongly considered, assessing its importance as noted in the current report and similar reports.

\section{REFERENCES}

1. Faropoulos K, Panagiotopoulos V, Partheni M, Tzortzidis F, Konstatinou D: Therapeutic management of intraventricular cavernoma: Case series and review of the literature. J Neurol Surg 76:233-239, 2015

2. Finkelburg R: Zur Differential diagnose zwischen kleinhirntumoren und chronischen hydrocephalus. (Zugleich ein beitrag zur kenntnis der angiome des zentral nerven systems). Dtsch Z Nervenheilkd 29:135-151, 1905

3. Heckl S, Aschoff A, Kunze S: Radiation-induced cavernous hemangiomas of the brain: A late effect predominantly in children. Cancer 94: 3285-3291, 2002

4. Kasliwal MK, Sharma BS: Giant intraventricular mass arising from the septum pellucidum. Journal of Clinical Neuroscience 18: 1108, 2011

5. Katoha M, Sawamurab $\mathrm{Y}$, Moriwaki T, Yoshino M, Aoki T, Abumyia T, Imamura H, Aida T: A case of cavernous angioma in the septum pellucidum. Clinical Neurology and Neurosurgery 115: 1126-1127, 2013

6. Mouchtouris N, Chalouhi N, Chitale A, Starke RM, Tjoumakaris $\mathrm{SI}$, Rosenwasser RH, Jabour PM: Management of cerebral cavernous malformations: From diagnosis to treatment. Scientific World Journal 2015:808314, 2015

7. Muzumdar D, Avinash KM, Ramdasi R: Cavernoma of the septum pellucidum in the region of foramen of Monro. Neurology India 63:68-71, 2015

8. Picolas C, Faropoulos K, Kekempanou K, Gatzounis G: Case report of a septum pellucidum cavernoma surgically resected via inferior parietal approach and short literature review. Open Journal of Modern Neurosurgery 6:68-75, 2016

9. Vitorino-Araújo JL, Veiga JCE, Wen HT, de Andrade AF, Teixeira MF, Otoch JP, Rhoton AL Jr, Preul MC, Spetzler RF, Figueiredo EG: Comparative anatomiscal analysis of the transcallosaltranschoroidal and transcallosal-transforniceal-transchoroidal approaches to the third ventricle. Journal of Neurosurgery 4:1-10, 2016 